\title{
Human embryonic stem cell technology: large scale cell amplification and differentiation
}

\author{
Steve K.W. Oh* and Andre B.H. Choo \\ Stem Cell Group, Bioprocessing Technology Institute, 20 Biopolis Way, \#06 - 01 Centros, Singapore 138668; \\ *Author for correspondence (e-mail: steve_oh@bti.a-star.edu.sg; fax: +65-6478 9561)
}

Received 7 October 2005; accepted 7 October 2005

Key words: Bioreactor, Expansion, Human embryonic stem cell, Pluripotency, Scale-up, Serum-free feeder-free culture

\begin{abstract}
Embryonic stem cells (ESC) hold the promise of overcoming many diseases as potential sources of, for example, dopaminergic neural cells for Parkinson's Disease to pancreatic islets to relieve diabetic patients of their daily insulin injections. While an embryo has the innate capacity to develop fully functional differentiated tissues; biologists are finding that it is much more complex to derive singular, pure populations of primary cells from the highly versatile ESC from this embryonic parent. Thus, a substantial investment in developing the technologies to expand and differentiate these cells is required in the next decade to move this promise into reality. In this review we document the current standard assays for characterising human ESC (hESC), the status of 'defined' feeder-free culture conditions for undifferentiated hESC growth, examine the quality controls that will be required to be established for monitoring their growth, review current methods for expansion and differentiation, and speculate on the possible routes of scaling up the differentiation of hESC to therapeutic quantities.
\end{abstract}

\section{Introduction}

Embryonic stem cells are pluripotent, capable of differentiation as well as unlimited self-renewal which theoretically make them ideal for replacement, repair or regeneration of tissues and organs. This review covers the current state of the known art and developments in the technologies needed for identifying and manipulating these versatile cells towards their full potentials.

\section{Human embryonic stem cells}

\section{What is a human embryonic stem cell?}

There are several important features that define an embryonic stem cell (ESC); these are listed in
Table 1 (Pera et al. 2000). Typically the characteristic transcription factors include Oct4, Nanog and Sox2; human telomerase and alkaline phosphatase are also highly expressed, along with a panel of cell surface markers including SSEA-3 and SSEA-4, which detect the globoseries glycolipids, and Tra-1-60, Tra-1-81 and GCTM-2 which detect proteoglycans such as keratan sulphate. In addition, when human ESC (hESC) are cultured in suspension, they form embryoid body structures which, when left to differentiate without manipulation, can give rise to a variety of phenotypes. These same cells, when injected into severe combined immuno-deficient (SCID) mice, form teratomas which consist of tissues from all three of the germ layers, ecto-, meso- and endoderm. While surface antigen markers have been used for the identification of hESC in various labs, there has 
Table 1. Characteristic markers of hESCs.

Transcription factors

Surface markers

Other markers

In vitro differentiation

In vivo differentiation (SCID assay)

Karyotype

Doubling time
Oct4, Nanog, Sox2

Stage specific embryonic antigens SSEA-3/4, Tumour related antigens Tra-1-60/1-81, GCTM-2

Human telomerase enzyme, Alkaline phosphatase

Neural lineage, Haematopoietic lineage, Cardiac lineage

Ectoderm, Mesoderm, Endoderm

23 pairs of chromosomes

Typically $30 \pm 2 \mathrm{~h}$ (Ranges from 24 to $48 \mathrm{~h}$ ) not been a concerted effort to compare a broad range of hESC lines in different labs for the proportion of expression of these markers. It is possible that the different hESC isolates, method of derivation and culture conditions may cause heterogeneity of these markers. Thus the International Stem Cell Initiative led by Prof. Peter Andrews was organized to characterize $77 \mathrm{hESC}$ cell lines from 15 nations with the goal of determining if there is any variability in antigen marker levels, as well as gene expression upon differentiation, between these cell lines (Andrews et al. 2005). This effort is important as no other stem cell community has planned such an ambitious undertaking to date.

\section{Defining culture conditions for hESC}

In any attempt to scale up hESC for the purpose of clinical studies, a defined culture system will be a first irreducible goal (Bongso et al. 2005). Until recently, hESC have been cultured on a variety of feeder cell lines or the conditioned media (CM) made from these cells (Thomson et al. 1998; Choo et al. 2004). However, in the first half of this year, we have made significant progress in understanding how to maintain hESC in feeder-free environments, by supplementing with either basic fibroblastic growth factor (FGF-2) alone (Li et al. 2005; $\mathrm{Xu}$ et al. 2005a) or in combination with either noggin (Wang et al. 2005; Xu et al. 2005b) or with activin A (Beattie et al. 2005). These conditions summarized in Table 2, lead one to speculate that hESC are much more complex and versatile than mouse ESC (mESC) in the ways they regulate self-renewal and prevent differentiation. In essence, besides the traditional feeder cultures or CM from feeders; one camp has identified FGF-2 signalling to be critically important in selfrenewal (see the first four references in Table 2), while another group postulates that the transforming growth factor beta (TGF $\beta$ ) signalling pathways are necessary for preventing differentiation by default, (see last four references in Table 2). These latest reports seem to suggest that hESC requires FGF-2 for self-renewal while at the same time the blockage of BMP signalling is needed in retaining their phenotype. This is a distinctly different paradigm from mESC pluripotency which is solely dependent on leukaemia inhibitory factor (LIF) which activates

Table 2. Growth factors and putative pathways in maintaining hESC pluripotency.

\begin{tabular}{lll}
\hline Culture conditions of hESC & Putative pathways involved in pluripotency & Reference \\
\hline FGF-2 alone, hESC seeded at high densities & FGF-2 signalling & Draper et al. (2004a) \\
$\begin{array}{l}\text { FGF-2 alone at high concentrations (or with } \\
\text { Flt ligand) }\end{array}$ & FGF-2 signalling & Xu et al. (2005a) \\
FGF-2 and noggin & FGF-2 signalling, suppression & Xu et al. (2005b) \\
FGF-2 alone at high concentrations & of BMP signalling & Li et al. (2005) \\
TGF $\beta$ and FGF-2 & FGF-2 signalling & Amit et al. (2004) \\
Activin A, and FGF-2 & TGF $\beta /$ FGF-2 signalling? & Besser (2004) \\
Activin A, nicotinamide and keratinocyte & Activin A signalling, SMAD2/3 activation & Beattie et al. (2005) \\
growth factor & TGF $\beta /$ Activin A signalling & James et al. (2005) \\
Activin A or GSK3 $\beta$ inhibitor & TGF $\beta /$ Activin A signalling, & \\
& SMAD2/3 activation &
\end{tabular}




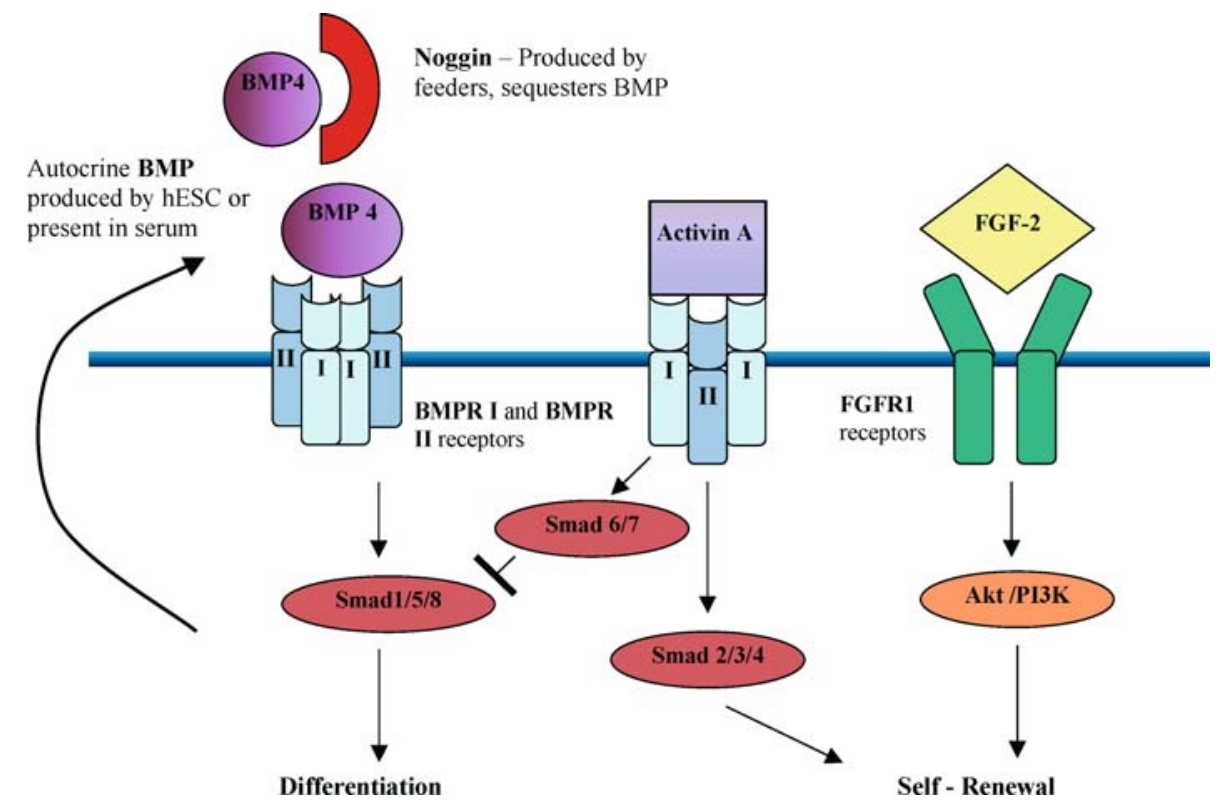

Figure 1. A hypothetical model of the action of different ligands in maintaining hESC pluripotency. BMP4 which is present in serum and produced by hESC binds to BMPR I and II receptors to activate Smad 1/5/8 leading to differentiation. Noggin produced by feeders can sequester BMP preventing its action. Alternatively Activin A, which belongs to the BMP family can compete for the BMPR I and II receptors to activate Smad 2/3/4 leading to self-renewal and block the actions of Smad 1/5/8 via Smad 6/7. FGF-2 is postulated to bind to FGFR1 receptors and activate the Akt/PI3K pathway which is required for self-renewal.

the Jak/Stat pathway, while this pathway fails to maintain self-renewal in hESC (Daheron et al. 2004).

It appears that the bone morphogenetic proteins, BMP-2 and -4, which may be present in serum or serum replacer, and possibly released from hESC themselves (Wang et al. 2005; Xu et al. 2005b), may initiate differentiation by binding to a pair of BMPR I and BMPR II complexes present on animal cells, so activating the Smad 1/5/8 pathway (Balemans and Van Hul 2002; Nohe et al. 2004). However, the activity of BMP-4 can be attenuated by adding high concentrations of noggin, which sequesters BMP-4, as several groups have demonstrated (Pera et al. 2004; Gerrard et al. 2005; Wang et al. 2005; Xu et al. 2005b). Noggin at high concentrations antagonises BMP by mimicking the BMPR I receptor and binding tightly to it, as shown in recent crytallographic studies (Groppe et al. 2002).

Complementary to this, other groups have shown that activin A supplemented to the media can also exert the same effect as CM from feeders (Besser 2004; Beattie et al. 2005; James et al. 2005). Activin A, which belongs to the TGF $\beta$ family, also acts through the promiscuous BMPR I receptor to form a heterodimer with the BMPR II receptor, causing the downstream phosphorylation of Smads 2/3/4 (Dale and Jones 1999; Besser 2004). This has been shown to activate the inhibitors of Nodal signalling, Lefty A \& B known to be necessary for maintaining pluripotency (Besser 2004). Thus it is possible that the addition of activin A competes for the BMPR I and II receptors, which would otherwise bind to BMP-4 causing differentiation. Activation of one set of these heterodimeric receptors lead to self-renewal while the other causes differentiation. In addition, the binding of Activin A to the BMPR I and II receptors leads to Smad 6 and 7 activation, which inhibits the functions of Smads 1/5/8 (Balemans and Van Hul 2002). A hypothetical model of stem cell maintenance summarising the action of these different factors is depicted in Figure 1.

A proteomics approach has been taken by a team in Australia in order to decipher the identity of the growth factors in CM and they have identified gremlin, which like noggin is a BMP antagonist (Prowse et al. 2005). To date however, there has been no published report of TGF $\beta$ or activin 
being found in $\mathrm{CM}$ or feeders. Our own structural studies of CM have identified several growth factors, but none belong to the TGF $\beta$ family (unpublished data).

A caution about the use of noggin in culture is that it appears to predispose hESC to differentiate towards the neural lineage (Pera et al. 2004; Gerrard et al. 2005). Thus further investigations need to be carried out to determine if these factors can truly maintain a pluripotent phenotype in long-term cultures. It would also be interesting to determine which of the BMPR I and BMPR II receptors on hESC bind to either BMP or activin, as there are several receptors within each class, each of which bind with different specificity and affinity to these ligands. Furthermore, the Smads activated by these receptor combinations and their subsequent control of transcription remains to be understood.

FGFs are an essential component in the media used for hESC cultures and insights have come from two recent studies as to how FGF-2 might act on hESC. hESC express all four FGF receptors, in the following order of abundance: FGFR1 > FGFR3 > FGFR4 $>$ FGFR2 (Dvorak et al. 2005). Phosphorylation of mitogenactivated protein kinase (MEK1/2) and its substrate ERK1/2 were observed in the presence of FGF-2. Interestingly, hESC also produced high molecular weight forms of endogenous FGF-2, which was speculated to play a role in autocrine signalling. Another group has apparently shown that the phosphatidylinositol 3-kinase (PI3K) Akt/ PKB signalling pathway is activated in the presence of FGF-2 and inhibition of this pathway leads to the differentiation of hESC (Kim et al. 2005). Less is known about how the FGF receptors activate downstream signalling pathways in hESC. Thus it appears that hESC are both very versatile and pliant in their response to a range of growth factors and that a fine balance is required for maintaining them in an undifferentiated state for long periods of culture.

A final comment concerning the current defined media conditions; it is preferable to eventually remove the serum replacer component which is prevalent in all of these studies. This is still derived from serum and contains a large amount of bovine serum albumin and other proteins. Work is ongoing in our group, for example, to simplify these culture conditions with components found in serum.

\section{Quality control of hESC}

A recent significant concern has been the observation of karyotypic abnormalities such as trisomy (3 chromosomes) and aneuploidy occurring during long-term maintenance of hESC. Two groups have suggested that mechanical cutting of colonies for passaging may be a more stable method of propagation (Buzzard et al. 2004; Mitalipova et al. 2005) than the use of enzymes for long-term maintenance of hESC (Draper et al. 2004b). It has been speculated however, that abnormal karyotypes are unlikely to survive in long-term culture unless there is a proliferative advantage (Peter Andrews, University of Sheffield, personal communication). In contrast, a prolonged study of several cell lines was not able to show any significant instabilities in long-term culture (Rosler et al. 2004). Furthermore, it is quite possible that shortterm passaging with enzymes ( $<15$ passages) will not prejudice the normal karyotype (Mitalipova et al. 2005). Nevertheless, karyotypic analysis will have to be routinely conducted in expanded hESC to prevent aneuploidy, which is associated with carcinogenesis. Interestingly, few other stem cell reports employ karyotyping as a standard, although a recent publication on mesenchymal stem cells shows that abnormal karyotypes can be detected if the cells are passaged for 4-5 months (Rubio et al. 2005). This is a far shorter period than hESC cultures which have been propagated for 2 years in a stable manner in our lab (unpublished data). Another concern is the presence of murine viruses such as retroviruses and murine leukaemia viruses (muLV) in some of the feeder layers that have been used in culture. However, a new report has shown no evidence for infection of hESC by feeder-derived muLV even after prolonged culture (Amit et al. 2005). But it has been demonstrated that if muLV is present, hESC can become infected, supporting the need for ongoing screening. Other contaminants such as prion proteins, host protein from cell lysates, cytokines and DNA will also need to be tested for routinely. Historically, epigenetic instability in mouse embryos, as exemplified by poor development, occurs if both the maternal or paternal genes are expressed. Thus a concern has been raised that genes that are not imprinted properly in hESC may lead to retarded tissue development. A keynote paper has just been published showing that 
three paternally expressed genes, IGF2, IPW and KCNQ1, are characteristically paternally expressed, while three others which are typically maternally expressed are also monoallelically expressed in several hESC lines (Rugg-Gunn et al. 2005). Thus it appears that epigenetic stability is the norm in hESC, which seems to give the field a 'green light' to move forward with differentiation studies. A final concern is the potential of hESC in generating an immune response in transplanted mice. Again in 2004 (Li et al. 2004), it was reported that these cells have the surprising property of relative 'immune privilege'. Both undifferentiated and differentiated hESC failed to stimulate proliferation of alloreactive primary human $\mathrm{T}$ cells, and in fact inhibited T-cell proliferation, giving hope that transplanted hESC derivatives may avoid rejection. One unexpected discovery was the report of hESC being capable of taking up substantial amounts of the potentially immunogenic non-human sialic acid, Neu5Gc from animal-derived serum replacements and mouse feeders (Martin et al. 2005). Exposure of these hESC to human sera containing antibodies specific to Neu5Gc sialic acid resulted in binding of $\mathrm{IgG}$, deposition of complement and cell killing. This reinforces the need to develop scaleable methods of hESC expansion in completely animal sourcefree, defined culture media.

\section{Methods for expansion and scale up}

As hESC have a high capacity for self-renewal, it is anticipated that the production of therapeutic quantities of differentiated cells will exploit this quality to enable the scale up of sufficient hESC (the 'starting material'), which would then be differentiated into progenitors or the final differentiated phenotype. As progenitors have much reduced replicative potential, expanding hESC numbers first is also a more efficient approach to scale up cells for regenerative therapies. Furthermore, existing methods yield differentiated progeny at very low efficiencies (vide infra). Both mESC and hESC are anchorage-dependent, and grow uniquely as colonies, so that current methods to scale them up have focused on the use of flat surfaces or matrices ( $\mathrm{Li}$ et al. 2003; Berrill et al. 2005; Fong et al. 2005). It has been demonstrated that mESC grow significantly better on a surface called petriperm (Oh et al. 2005), which triggered an expansion up to 64-fold, compared to 9-fold in Petri dishes over 6 days. Others have also achieved high density cultures in matrices, although the challenge here will be to expand hESC to high densities in porous matrices and yet still be able to harvest them easily for differentiation ( $\mathrm{Li}$ et al. 2003). Once ESC have been produced to significant quantities, they are typically differentiated as embryoid bodies consisting of a variety of cell types. These structures have been cultivated in both conventional stirred cultures with $\mathrm{mESC}$ and hESC encapsulated in gels (Dang et al. 2004), and human EBs have been grown in a rotating bioreactor (Gerecht-Nir et al. 2004a). In both cases these are very preliminary studies on a small scale; it will be interesting to see if these methods can produce sufficiently pure populations of differentiated cells for animal models and eventual clinical studies.

It would also be much more convenient to scale up hESC in suspension culture; however our own attempts to grow them attached on microcarriers or within alginate beads have been unsuccessful (see Figure $2 \mathrm{a}, \mathrm{b}$ ). As the hESC inoculum consists of relatively large clusters of 50 cells or more, they are about the size of commercially available microcarriers (about $150-200 \mu \mathrm{m}$ in diameter): thus, in our experience, it is not an easy task to attach hESC clusters to microcarriers. Immobilized hESC, when released from alginate beads after 1 week of growth, were also of low viability. We have further attempted to grow hESC in suspension in the presence of polymers to protect the cells from the effects of shear during agitation in $0.5 \%$ Dextran 8000, 0.5\% PEG 200, 0.5\% PEI 2000 , or $0.5 \%$ Pluronic; but in all cases, upon gentle agitation, cells died or did not proliferate significantly (see Figure 2c-f, respectively). All these conditions were unsuitable compared to control cultures on feeders or in feeder-free conditions on tissue culture plastic (Figure 2g, h). Mouse ESC have been successfully grown in suspension as aggregates; but, these cells are more robust and behave quite differently than hESC, which are more fragile and sensitive (unpublished data). Thus alternative strategies of suspension cultures might be attempted such as the use of large pore macroporous beads to facilitate seeding of large hESC clusters, or immobilized cultures coated with matrigel to increase viability. 

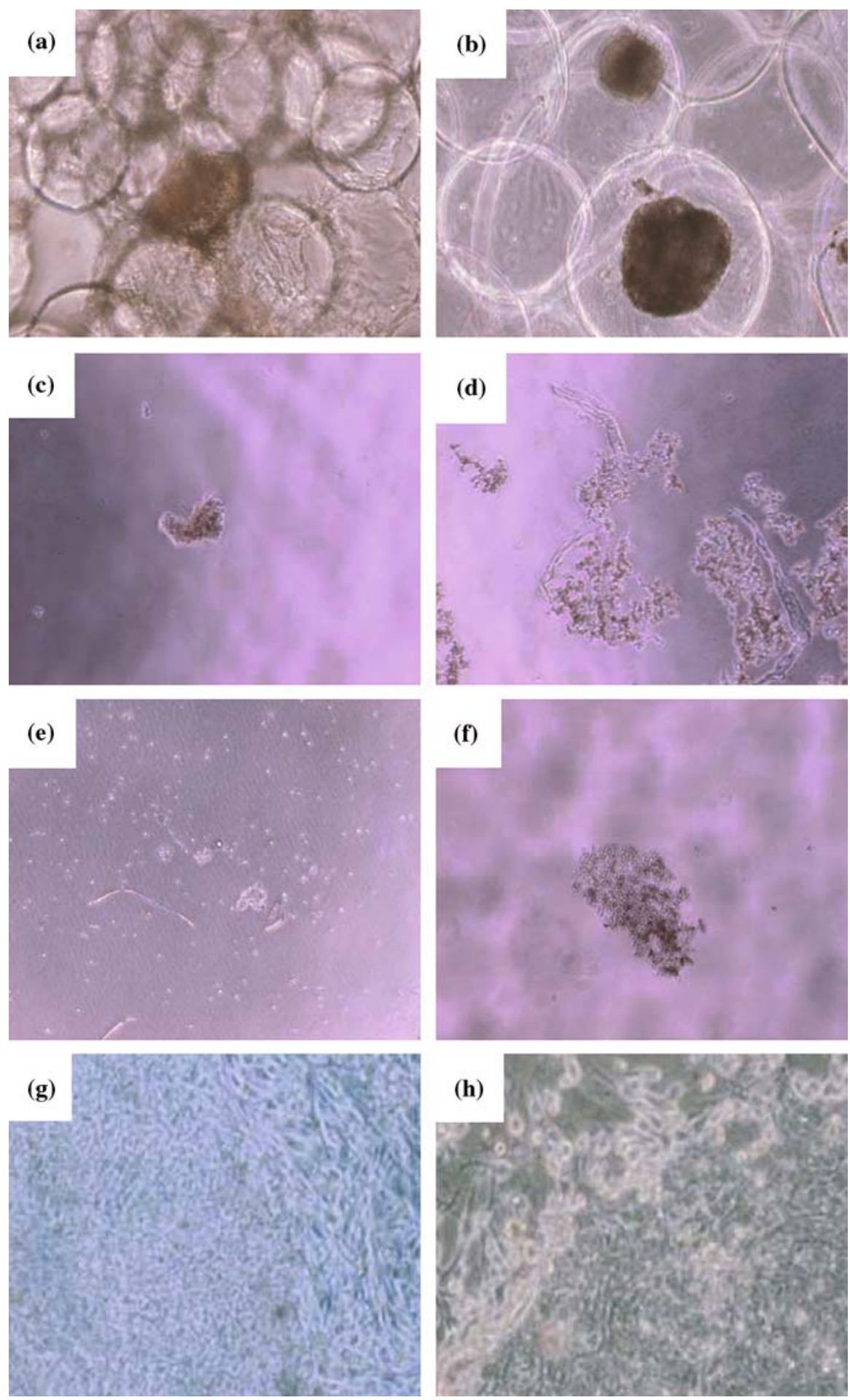

Figure 2. Attempts at growing hESC in suspension (a) attached to feeders on Cytodex 3 microcarriers (b) immobilized in alginate (c) in $0.5 \%$ Dextran 8000 (d) in $0.5 \%$ PEG 200 (e) in $0.5 \%$ PEI 2000 (f) in $0.5 \%$ Pluronic respectively, were unsuccessful. (g) and (h) shows control cultures of hESC grown on feeders and feeder free conditions. All pictures were taken at a magnification of 40x except for (a) which was taken at 200x. 


\section{Differentiation protocols}

Since their isolation, a large number of groups have shown the ability to differentiate hESC to a variety of lineages with varying levels of competency both in vivo and in vitro (Blum and Benvenisty 2005). These include, for example, neurons and glia which appear to be the default pathway for hESC differentiation (Reubinoff et al. 2001; Hornstein and Benvenisty 2004), while cardiomyocytes (Mummery et al. 2003; Passier et al. 2005), endothelial cells (Levenberg et al. 2002), blood cells (Murdoch et al. 2002), hepatocyte-like cells (Rambhatla et al. 2003) and insulinproducing clusters (Segev et al. 2004) have also been created. However, there is little or no data on the efficiencies of methods or a comparison of them, albeit anecdotal accounts suggest that the efficiencies are very low (in the order of single digit percentages). Taking the example of neural differentiation for potential application in Parkinson's Disease, one report has shown that PA6 stromal cells (Zeng et al. 2004) can generate dopaminergic neural cells, while another group has achieved this same lineage via the formation of neurospheres in serum-free culture (Schulz et al. 2004). In both cases, the time of differentiation was in the order of several weeks; however it is unclear if a feeder layer was more efficient than the serumfree approach, though obviously the latter has significant clinical advantages.

\section{Are differentiated cells also scaleable?}

While there have been preliminary reports of scaleable methods for differentiating hESC, there have been a few studies for differentiating mESC in bioreactors by the Zandstra group. For example, a comparison of three methods for producing embryoid bodies and cells of the haematopoietic lineage from mESC identified encapsulated gels as the preferred method (Dang et al. 2002) and a study of controlled hypoxic conditions yielded 3.7 times more cardiomyocytes than normoxic conditions (Bauwens et al. 2005). Others have demonstrated that human EBs can be scaled up in suspension, such as in small rotating bioreactors (Gerecht-Nir et al. 2004a), and tried to encourage differentiation on scaffolds (Gerecht-Nir et al. 2004b). However, these are early studies and more innovative and scaleable methods of differentiation and efficient harvest of the cells for animal studies clearly need to be explored.

Due to the vast possibilities of hESC, it is envisaged that the types of manufacturing processes to produce a particular lineage will be as varied and complex as the property of the target tissue. Exploiting the expansion capabilities of hESC, we envisage that a common theme will be the need to expand a large starting population of hESC as source material. After which the initiation of differentiation would occur through the formation of either human embryoid bodies (hEBs) or neurospheres in suspension cultures. An initial purification step to harvest the early progenitor population and to remove residual hESC will be required. At the next stage, some progenitor cells, for example the islet or cardiomyocyte clusters, which grow in suspension, could be expanded in suspension; whilst the neuronal progenitors would be grown on surfaces. A second stage of purification of progenitors will be required to remove contaminating cell types ensuring a relatively pure population of cells devoid of other lineages, This would be followed by further expansion of the final phenotype such as pancreatic islets either in suspension, or cardiomyocytes and dopaminergic neurons on surfaces with a separate cocktail of growth factors or feeder cells. A final purification step may be required where ideally one would want to have only the functional cell type. A schematic of possible processes for three different cell types is shown in Figure 3.

\section{Conclusions}

HESC have several well-characterized markers for their recognition that have been used by many laboratories; progress is also being made in identifying defined conditions for their expansion, free of feeders, without serum replacer. Human ESC culture will require unique quality control assays such as karyotyping, immunogenicity tests, elimination of residual hESC cells as well as the routine assays for detecting contaminants, like viruses, prions, host cell proteins, cytokines and DNA. Expansion of hESC is as yet confined to surfaces, and although some progress is being made in achieving higher cell densities, attempts at suspension culture have been unsuccessful. 


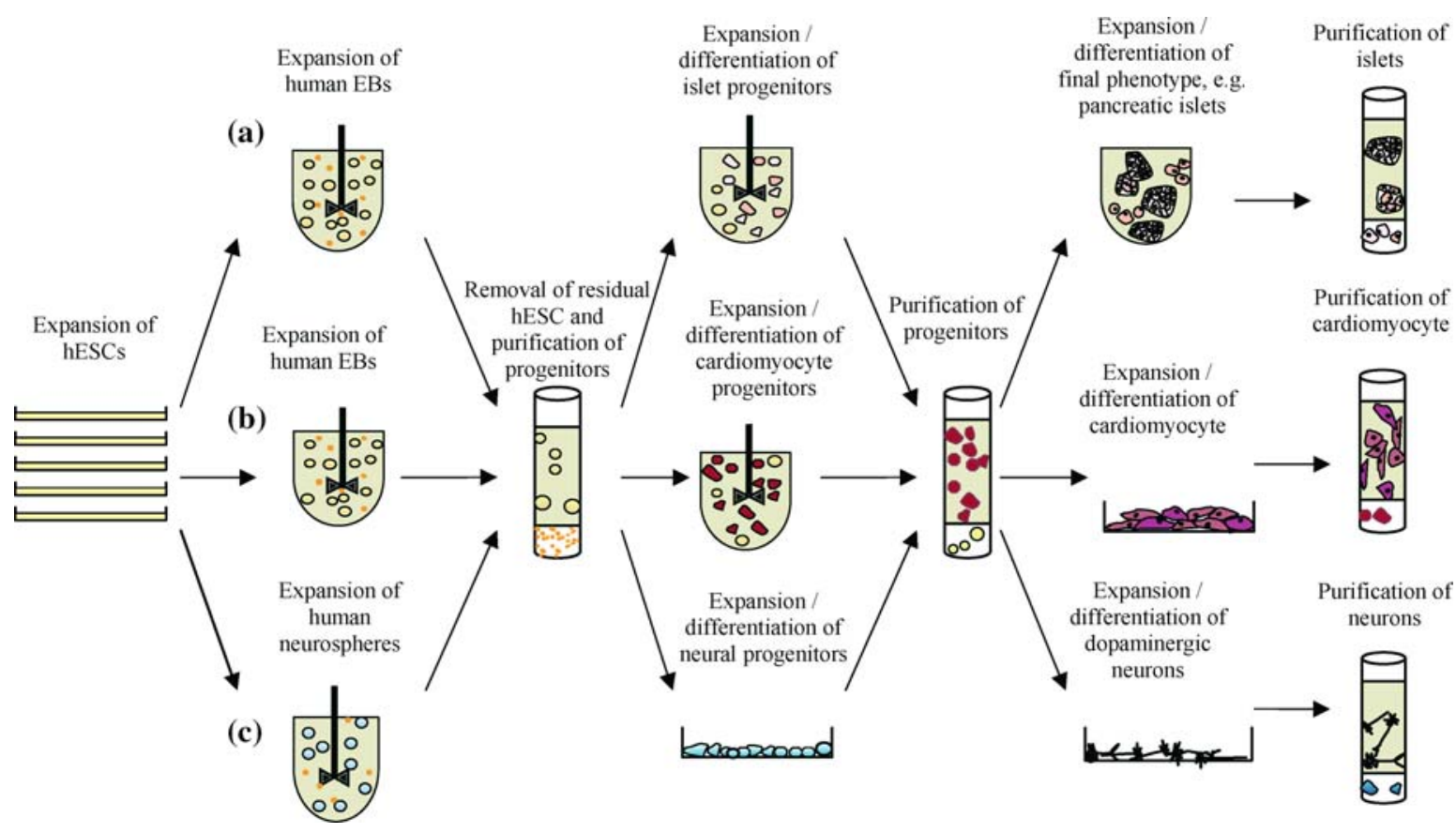

Figure 3. A schematic of possible future manufacturing systems in the expansion and differentiation of various lineages from hESC. The process would begin with generating large quantities of hESC which have an indefinite capability to expand. These resulting cells could be initiated to differentiate in suspension cultures as human embryoid bodies (hEBs) for a period of time. The hEBs would be separated to remove residual hESC and the target progenitor population selected for expansion. Then depending on whether the cell type required grows in suspension (e.g. islets) these would be grown in bioreactors (a), or if they require a combination of suspension culture and anchorage to a surface (e.g. cardiomyocytes), they would be grown accordingly (b). If the neural lineage is required, neurospheres could be cultured, undergo a separation step of enrichment for neural progenitors and eventually specific dopaminergic neurons grown on plastic culture surfaces (c). At the end of the expansion processes, ideally only the final phenotype is purified.

Differentiation protocols are available for a host of cell types, but optimization and better methods of scale up will need to be developed to generate sufficient cells for animal studies, as these are currently in their infancy.

\section{Acknowledgements}

We thank A*STAR, Singapore for generous funding of our research, Selena $\mathrm{Wu}$ for drawing Figures 1 and 3, Dr Victor Nurcombe, IMCB, Dr Jeremy Crook, ESI and Dr Ken Chan, BTI for critically reviewing this manuscript.

\section{References}

Amit M., Shariki C., Margulets V. and Itskovitz-Eldor J. 2004. Feeder layer- and serum-free culture of human embryonic stem cells. Biol. Reprod. 70: 837-845.
Amit M., Winkler M.E., Menke S., Bruning E., Buscher K., Denner J., Haverich A., Itskovitz-Eldor J. and Martin U. 2005. No evidence for infection of human embryonic stem cells by feeder cell-derived murine leukemia viruses. Stem Cells 23: 761-771.

Andrews P.W., Benvenisty N., McKay R., Pera M.F., Rossant J., Semb H. and Stacey G.N. 2005. The International Stem Cell Initiative: toward benchmarks for human embryonic stem cell research. Nat. Biotechnol. 23: 795-797.

Balemans W. and Van Hul W. 2002. Extracellular regulation of BMP signaling in vertebrates: a cocktail of modulators. Dev. Biol. 250: 231-250.

Bauwens C., Yin T., Dang S., Peerani R. and Zandstra P.W. 2005. Development of a perfusion fed bioreactor for embryonic stem cell-derived cardiomyocyte generation: oxygenmediated enhancement of cardiomyocyte output. Biotechnol. Bioeng. 90: 452-461.

Beattie G.M., Lopez A.D., Bucay N., Hinton A., Firpo M.T., King C.C. and Hayek A. 2005. Activin A maintains pluripotency of human embryonic stem cells in the absence of feeder layers. Stem Cells 23: 489-495.

Berrill A., Tan H.L., Wuang S.C., Fong W.J., Choo A. and Oh S.K.W. 2005. Assessment of stem cell markers during long term culture of mouse embryonic stem cells. Cytotechnology 44: 77-91. 
Besser D. 2004. Expression of nodal, lefty-A, and lefty-B in undifferentiated human embryonic stem cells requires activation of Smad2/3. J. Biol. Chem. 279: 45076-45084.

Blum B. and Benvenisty N. 2005. Differentiation in vivo and in vitro of human embryonic stem cells. In: Stem Cells: From Bench to Bedside. World Scientific Publishing Co. Pte. Ltd, pp. 123-143.

Bongso A., Richards M. and Fong C.-Y. 2005. From human embryos to clinically compliant embryonic stem cells: blastocyst culture, xeno-free derivation and cryopreservation, properties and applications of embryonic stem cells. In: Stem Cells: From Bench to Bedside. World Scientific Publishing Co. Pte. Ltd., pp 14-37.

Buzzard J.J., Gough N.M., Crook J.M. and Colman A. 2004. Karyotype of human ES cells during extended culture. Nat. Biotechnol. 22: 381-382.

Choo A.B., Padmanabhan J., Chin A.C. and Oh S.K. 2004. Expansion of pluripotent human embryonic stem cells on human feeders. Biotechnol. Bioeng. 88: 321-331.

Daheron L., Opitz S.L., Zaehres H., Lensch W.M., Andrews P.W., Itskovitz-Eldor J. and Daley G.Q. 2004. LIF/STAT3 signaling fails to maintain self-renewal of human embryonic stem cells. Stem Cells 22: 770-778.

Dale L. and Jones C.M. 1999. BMP signalling in early Xenopus development. Bioessays 21: 751-760.

Dang S.M., Gerecht-Nir S., Chen J., Itskovitz-Eldor J. and Zandstra P.W. 2004. Controlled, scalable embryonic stem cell differentiation culture. Stem Cells 22: 275-282.

Dang S.M., Kyba M., Perlingeiro R., Daley G.Q. and Zandstra P.W. 2002. Efficiency of embryoid body formation and hematopoietic development from embryonic stem cells in different culture systems. Biotechnol. Bioeng. 78: 442-453.

Draper J.S., Moore H.D., Ruban L.N., Gokhale P.J. and Andrews P.W. 2004a. Culture and characterization of human embryonic stem cells. Stem Cells Dev. 13: 325-336.

Draper J.S., Smith K., Gokhale P., Moore H.D., Maltby E., Johnson J., Meisner L., Zwaka T.P., Thomson J.A. and Andrews P.W. 2004b. Recurrent gain of chromosomes 17q and 12 in cultured human embryonic stem cells. Nat. Biotechnol. 22: 53-54.

Dvorak P., Dvorakova D., Koskova S., Vodinska M., Najvirtova M., Krekac D. and Hampl A. 2005. Expression and potential role of fibroblast growth factor 2 and its receptors in human embryonic stem cells. Stem Cells. 23: $1200-1211$.

Fong W.J., Tan H.L., Choo A. and Oh S.K.W. 2005. Perfusion cultures of human embryonic stem cells. Bioprocess. Biosyst. Eng. Jun1; (Epub ahead of print)

Gerecht-Nir S., Cohen S. and Itskovitz-Eldor J. 2004a. Bioreactor cultivation enhances the efficiency of human embryoid body (hEB) formation and differentiation. Biotechnol. Bioeng. 86: 493-502.

Gerecht-Nir S., Cohen S., Ziskind A. and Itskovitz-Eldor J. 2004b. Three-dimensional porous alginate scaffolds provide a conducive environment for generation of well-vascularized embryoid bodies from human embryonic stem cells. Biotechnol. Bioeng. 88: 313-320.

Gerrard L., Rodgers L. and Cui W. 2005. Differentiation of human embryonic stem cells to neural lineages in adherent culture by blocking BMP signaling. Stem Cells. 23: 1234-1241.
Groppe J., Greenwald J., Wiater E., Rodriguez-Leon J., Economides A.N., Kwiatkowski W., Affolter M., Vale W.W., Belmonte J.C. and Choe S. 2002. Structural basis of BMP signalling inhibition by the cystine knot protein Noggin. Nature 420: 636-642.

Hornstein E. and Benvenisty N. 2004. The "brainy side" of human embryonic stem cells. J. Neurosci. Res. 76: 169-173.

James D., Levine A.J., Besser D. and Hemmati-Brivanlou A. 2005. TGFbeta/activin/nodal signaling is necessary for the maintenance of pluripotency in human embryonic stem cells. Development 132: 1273-1282.

Kim S.J., Cheon S.H., Yoo S.J., Kwon J., Park J.H., Kim C.G., Rhee K., You S., Lee J.Y., Roh S.I. and Yoon H.S. 2005. Contribution of the $\mathrm{PI} 3 \mathrm{~K} / \mathrm{Akt} / \mathrm{PKB}$ signal pathway to maintenance of self-renewal in human embryonic stem cells. FEBS Lett. 579: 534-540.

Levenberg S., Golub J.S., Amit M., Itskovitz-Eldor J. and Langer R. 2002. Endothelial cells derived from human embryonic stem cells. Proc. Natl. Acad. Sci. USA 99: 43914396.

Li L., Baroja M.L., Majumdar A., Chadwick K., Rouleau A., Gallacher L., Ferber I., Lebkowski J., Martin T., Madrenas J. and Bhatia M. 2004. Human embryonic stem cells possess immune-privileged properties. Stem Cells 22: 448-456.

Li Y., Kniss D.A., Lasky L.C. and Yang S-T. 2003. Culture and differentiation of murine embryonic stem cell on a threedimensional fibrous matrix. Cytotechnology 41: 23-35.

Li Y., Powell S., Brunette E., Lebkowski J. and Mandalam R. 2005. Expansion of human embryonic stem cells in defined serum-free medium devoid of animal-derived products. Biotechnol. Bioeng. 91: 688-698.

Martin M.J., Muotri A., Gage F. and Varki A. 2005. Human embryonic stem cells express an immunogenic nonhuman sialic acid. Nat. Med. 11: 228-232.

Mitalipova M.M., Rao R.R., Hoyer D.M., Johnson J.A., Meisner L.F., Jones K.L., Dalton S. and Stice S.L. 2005. Preserving the genetic integrity of human embryonic stem cells. Nat. Biotechnol. 23: 19-20.

Mummery C., Ward-van Oostwaard D., Doevendans P., Spijker R., van den B.S., Hassink R., van der H.M., Opthof T., Pera M., de la Riviere A.B., Passier R. and Tertoolen L. 2003. Differentiation of human embryonic stem cells to cardiomyocytes: role of coculture with visceral endoderm-like cells. Circulation 107: 2733-2740.

Murdoch B., Gallacher L., Chadwick K., Fellows F. and Bhatia M. 2002. Human embryonic-derived hematopoietic repopulating cells require distinct factors to sustain in vivo repopulating function. Exp. Hematol. 30: 598-605.

Nohe A., Keating E., Knaus P. and Petersen N.O. 2004. Signal transduction of bone morphogenetic protein receptors. Cell Signal. 16: 291-299.

Oh S.K.W., Fong W.J., Teo Y.W., Tan H.L., Padmanabhan J., Chin A.C.P. and Choo A.B.H. 2005. High density cultures of embryonic stem cells. Biotechnol. Bioeng. 91: 523-533.

Passier R., Oostwaard D.W., Snapper J., Kloots J., Hassink R.J., Kuijk E., Roelen B., de la Riviere A.B. and Mummery C. 2005. Increased cardiomyocyte differentiation from human embryonic stem cells in serum-free cultures. Stem Cells 23: 772-780.

Pera M.F., Andrade J., Houssami S., Reubinoff B., Trounson A., Stanley E.G., Ward-van Oostwaard D. and Mummery C. 
2004. Regulation of human embryonic stem cell differentiation by BMP-2 and its antagonist noggin. J. Cell. Sci. 117: 12691280.

Pera M.F., Reubinoff B. and Trounson A. 2000. Human embryonic stem cells. J. Cell Sci. 113(Pt 1): 5-10.

Prowse A.B., McQuade L.R., Bryant K.J., Van Dyk D.D., Tuch B.E. and Gray P.P. 2005. A proteome analysis of conditioned media from human neonatal fibroblasts used in the maintenance of human embryonic stem cells. Proteomics 5: 978-989.

Rambhatla L., Chiu C.P., Kundu P., Peng Y. and Carpenter M.K. 2003. Generation of hepatocyte-like cells from human embryonic stem cells. Cell Transplant. 12: 1-11.

Reubinoff B.E., Itsykson P., Turetsky T., Pera M.F., Reinhartz E., Itzik A. and Ben Hur T. 2001. Neural progenitors from human embryonic stem cells. Nat. Biotechnol. 19: 1134-1140.

Rosler E.S., Fisk G.J., Ares X., Irving J., Miura T., Rao M.S. and Carpenter M.K. 2004. Long-term culture of human embryonic stem cells in feeder-free conditions. Dev. Dyn. 229: 259-274.

Rubio D., Garcia-Castro J., Martin M.C., de la F.R., Cigudosa J.C., Lloyd A.C. and Bernad A. 2005. Spontaneous human adult stem cell transformation. Cancer Res. 65: 3035-3039.

Rugg-Gunn P.J., Ferguson-Smith A.C. and Pedersen R.A. 2005. Epigenetic status of human embryonic stem cells. Nat. Genet. 37: 585-587.

Schulz T.C., Noggle S.A., Palmarini G.M., Weiler D.A., Lyons I.G., Pensa K.A., Meedeniya A.C., Davidson B.P., Lambert N.A. and Condie B.G. 2004. Differentiation of human embryonic stem cells to dopaminergic neurons in serum-free suspension culture. Stem Cells 22: 1218-1238.

Segev H., Fishman B., Ziskind A., Shulman M. and ItskovitzEldor J. 2004. Differentiation of human embryonic stem cells into insulin-producing clusters. Stem Cells 22: 265-274.

Thomson J.A., Itskovitz-Eldor J., Shapiro S.S., Waknitz M.A., Swiergiel J.J., Marshall V.S. and Jones J.M. 1998. Embryonic stem cell lines derived from human blastocysts. Science 282: $1145-1147$.

Wang G., Zhang H., Zhao Y., Li J., Cai J., Wang P., Meng S., Feng J., Miao C., Ding M., Li D. and Deng H. 2005. Noggin and bFGF cooperate to maintain the pluripotency of human embryonic stem cells in the absence of feeder layers. Biochem. Biophys. Res. Commun. 330: 934-942.

Xu C., Rosler E., Jiang J., Lebkowski J.S., Gold J.D., O'Sullivan C., Delavan-Boorsma K., Mok M., Bronstein A. and Carpenter M.K. 2005a. Basic fibroblast growth factor supports undifferentiated human embryonic stem cell growth without conditioned medium. Stem Cells 23: 315-323.

Xu R.H., Peck R.M., Li D.S., Feng X., Ludwig T. and Thomson J.A. 2005b. Basic FGF and suppression of BMP signaling sustain undifferentiated proliferation of human ES cells. Nat. Methods 2: 185-190.

Zeng X., Cai J., Chen J., Luo Y., You Z.B., Fotter E., Wang Y., Harvey B., Miura T., Backman C., Chen G.J., Rao M.S. and Freed W.J. 2004. Dopaminergic differentiation of human embryonic stem cells. Stem Cells 22: 925-940. 